\title{
Hydrogen Peroxide Versus Hydrogen Generation at Bipolar Pd/Au Nano-catalysts Grown into an Intrinsically Microporous Polyamine (PIM-EA-TB)
}

\author{
Lina Wang ${ }^{1} \cdot$ Mariolino Carta ${ }^{2} \cdot$ Richard Malpass-Evans $^{3} \cdot$ Neil B. McKeown $^{3} \cdot$ Philip J. Fletcher $^{4} \cdot$ Diana Lednitzky $^{4}$. \\ Frank Marken ${ }^{1}$ (1)
}

Accepted: 25 September 2021 / Published online: 9 October 2021

(c) The Author(s) 2021

\begin{abstract}
Binding of $\mathrm{PdCl}_{4}{ }^{2-}$ into the polymer of intrinsic microporosity PIM-EA-TB (on a Nylon mesh substrate) followed by borohydride reduction leads to uncapped $\operatorname{Pd}(0)$ nano-catalysts with typically $3.2 \pm 0.2 \mathrm{~nm}$ diameter embedded within the microporous polymer host structure. Spontaneous reaction of $\operatorname{Pd}(0)$ with formic acid and oxygen is shown to result in the competing formation of (i) hydrogen peroxide (at low formic acid concentration in air; with optimum $\mathrm{H}_{2} \mathrm{O}_{2}$ yield at $2 \mathrm{mM}$ $\mathrm{HCOOH}$ ), (ii) water, or (iii) hydrogen (at higher formic acid concentration or under argon). Next, a spontaneous electroless gold deposition process is employed to attach gold (typically 10- to 35-nm diameter) to the nano-palladium in PIM-EA-TB to give an order of magnitude enhanced production of $\mathrm{H}_{2} \mathrm{O}_{2}$ with high yields even at higher $\mathrm{HCOOH}$ concentration (suppressing hydrogen evolution). Pd and Au work hand-in-hand as bipolar electrocatalysts. A Clark probe method is developed to assess the catalyst efficiency (based on competing oxygen removal and hydrogen production) and a mass spectrometry method is developed to monitor/optimise the rate of production of hydrogen peroxide. Heterogenised Pd/Au@PIM-EA-TB catalysts are effective and allow easy catalyst recovery and reuse for hydrogen peroxide production.
\end{abstract}

Keywords Biomass $\cdot$ Disinfection $\cdot$ Heterogenised palladium $\cdot$ Epoxidation $\cdot$ Hydrogen

\section{Introduction}

Microporous environments are commonly employed for immobilisation of catalysts (i) to control/restrict reagent access, (ii) to enhance the accessible catalyst surface area, (iii) to recover and re-use catalysts, and (iv) to improve the catalyst micro-environment and catalyst efficiency for example for palladium catalysts [1]. Palladium has found

Frank Marken

f.marken@bath.ac.uk

1 Department of Chemistry, University of Bath, Claverton Down, Bath BA2 7AY, UK

2 Department of Chemistry, College of Science, Swansea University, Grove Building, Singleton Park, SA2 8PP Swansea, UK

3 School of Chemistry, University of Edinburgh, Joseph Black Building, West Mains Road, Edinburgh EH9 3JJ, Scotland, UK

4 Materials \& Chemical Characterisation Facility, University of Bath, Bath BA2 7AY, MC, UK a plethora of applications in catalysis in processes ranging from $\mathrm{C}-\mathrm{C}$ coupling chemistry [2] and $\mathrm{N}$-alkylation, [3] in $\mathrm{H}_{2} \mathrm{O}_{2}$ production $[4,5]$ (see also $\mathrm{Pd}-\mathrm{Au}$ catalysis for "green" $\mathrm{H}_{2} \mathrm{O}_{2}$ production [6] and for the selective oxidation of methane [7], alcohol oxidation [8], in hydrogen generation from formic acid,[9] in electrocatalysis [10], and in a wide range of catalytic reduction reactions [11]. Immobilisation of $\mathrm{Pd}$ nanoparticles into microporous hosts is linked to enhanced catalytic reactivity as long as (i) host-guest interactions do not cause blocking and (ii) permeation of reactants into the host is effective. There is one previous report on the immobilisation of $\mathrm{Pd}$ nanoparticle catalysts into the polymer of intrinsic microporosity (abbreviated PIM) PIM-1 [12]. Fibrous PIM-1 with Pd nanoparticles embedded were obtained by electrospinning and employed in the catalytic reduction of nitroaromatics. It was shown that the PIM-1 provided selectivity towards the more strongly absorbing reactants and good permeation. Palladium inside of the microporous PIM-1 was demonstrated to be catalytically active. Palladium catalysts have been immobilised in other types of microporous hosts such as metal-organic 
frameworks [13]. Here, palladium is immobilised into the polymer of intrinsic microporosity PIM-EA-TB (see molecular structure in Fig. 1).

The development of polymers of intrinsic microporosity (PIMs) was linked initially to the formation of gas permeable and gas-separation membrane materials[14, 15]. Only recently have wet-chemical applications for intrinsically microporous polymers emerged, for example, in electrochemistry $[16,17]$, in electrocatalysis with embedded molecular catalysts [18] or embedded nanoparticle catalysts for hydrogen production $[19,20]$, and for hydrogen peroxide [21] production. PIM-EA-TB offers a microporous host material with typically $1000 \mathrm{~m}^{2} \mathrm{~g}^{-1}$ surface area (based on Brunauer-Emmett-Teller nitrogen adsorption data [22]) and with rigid microchannels of typically $1-2 \mathrm{~nm}$ diameter. Films of PIM-EA-TB on electrodes or sensors are produced by cast deposition from solvent [23].

Hydrogen peroxide formation is important in disinfection [24], in biomass break-down [25, 26], in pollution treatment [27], and in many further areas of chemical technologies [28]. Hydrogen peroxide can be generated conveniently from ambient oxygen, but the efficiency for this process is often problematic primarily due to unwanted over-reduction or disproportionation of $\mathrm{H}_{2} \mathrm{O}_{2}$ into $\mathrm{H}_{2} \mathrm{O} / \mathrm{O}_{2}$. New types of sustainable single-atom catalysts for the conversion of oxygen into hydrogen peroxide are under development [29]. Although photolytic processes are successfully employed to drive the reduction of $\mathrm{O}_{2}$ to $\mathrm{H}_{2} \mathrm{O}_{2}$ [30], there are also some successful dark chemical processes based on ambient oxygen and chemical reducing agents such as glucose [31] or formic acid [32].

In this report, the immobilisation/heterogenisation of a $\mathrm{Pd}$ catalyst or a $\mathrm{Pd} / \mathrm{Au}$ catalyst into the micropores of the molecularly rigid PIM-EA-TB polyamine is investigated. It is shown that $\mathrm{Pd}$ nanoparticles of typically 3.2-nm diameter are readily synthesised by absorption of $\mathrm{PdCl}_{4}{ }^{2-}$ followed by borohydride reduction. These "guest" nanoparticles are active for hydrogen generation from formic acid due to PIMEA-TB not blocking the surface of the catalyst and effective permeation of formic acid. Both hydrogen production and oxygen consumption are monitored in situ with a Clark probe [33] (Fig. 1A) and employing Nylon mesh substrates. Processes at the palladium catalyst are tentatively suggested to be based on (A) oxygen consumption (see processes 1 and 2) and based on (B) hydrogen production (process 3 ).

Process $1: \mathrm{HCOOH}+\mathrm{O}_{2} \rightleftarrows \mathrm{CO}_{2}+\mathrm{H}_{2} \mathrm{O}_{2}$

Process 2: $\mathrm{HCOOH}+\mathrm{H}_{2} \mathrm{O}_{2} \rightleftarrows \mathrm{CO}_{2}+2 \mathrm{H}_{2} \mathrm{O}$

Process $3: \mathrm{HCOOH} \rightleftarrows \mathrm{CO}_{2}+\mathrm{H}_{2}$

Spontaneous gold growth onto the palladium nanoparticles as nucleation sites is employed to moderate catalyst activity for hydrogen generation and to enhance the rate of hydrogen peroxide production by an order of magnitude. The competing mechanisms, the bipolar nature of the $\mathrm{Pd} / \mathrm{Au}$ catalyst, and the role of the polymer of intrinsic microscopy are discussed.

\section{Experimental}

\section{Reagents}

$\mathrm{HCl}$ (ACS reagent, 37\%), $\mathrm{PdCl}_{2}(99 \%), \mathrm{NaBH}_{4}$ (powder, $98 \%), \mathrm{KAuCl}_{4}(98 \%), \mathrm{H}_{3} \mathrm{PO}_{4}$ (85 wt.\% solution, ACS Reagent), $\mathrm{HCOOH}$ (96\%, ACS Reagent), $\mathrm{Na}_{2} \mathrm{CO}_{3}$ (powder, $\geq 99.5 \%$, ACS Reagent), and p-nitrophenylboronic acid $(\geq 95.0 \%)$ were purchased from Sigma-Aldrich. $\mathrm{H}_{2} \mathrm{O}_{2}$ (ACS Reagent, 30 wt. $\%$ in $\mathrm{H}_{2} \mathrm{O}$ ) and dimethyl sulfoxide (DMSO, for HPLC, $\geq 99.7 \%$ ) were products from Honeywell. $\mathrm{NaHCO}_{3}(\geq 99.7 \%)$ and $\mathrm{NaOH}$ (pellets, laboratory reagent grade) were obtained from Fluka. Jovitec universal $\mathrm{pH}$ test paper ( $\mathrm{pH}$ full range 1-14) was applied to monitor the $\mathrm{pH}$ value of solutions in the $\mathrm{H}_{2} \mathrm{O}_{2}$ quantification experiments. PIM-EA-TB was synthesised following the literature recipe [34]. Nylon mesh from 75- $\mu$ m diameter Nylon was purchased from Amazon.com (therpin reusable Nylon fine mesh food strainer bag).
Fig. 1 A Schematic drawing of a Clark probe for in situ analysis of oxygen consumption and hydrogen production. B Molecular structure of PIM-EA-TB

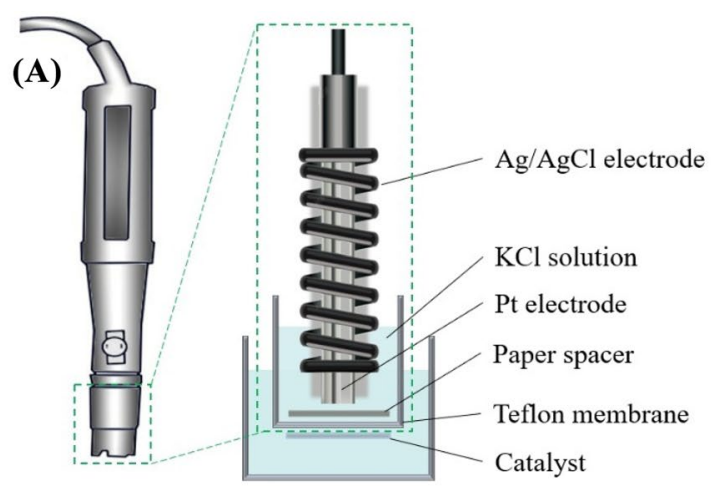

(B)

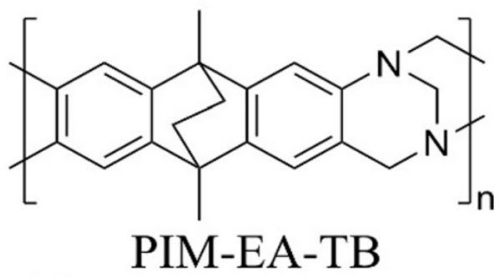




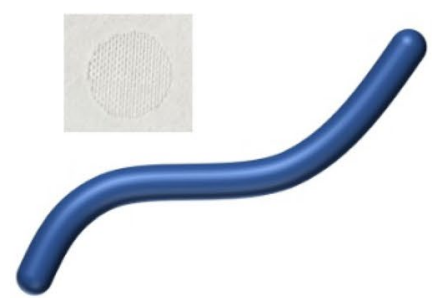

Nylon
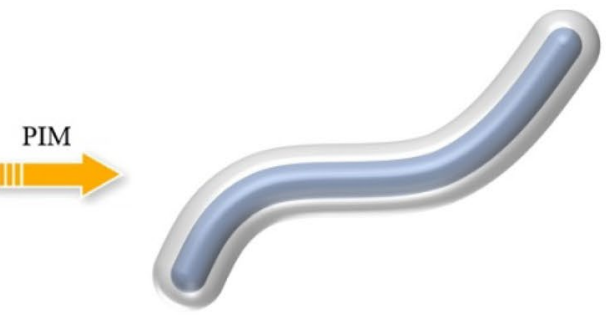

Nylon / PIM-EA-TB

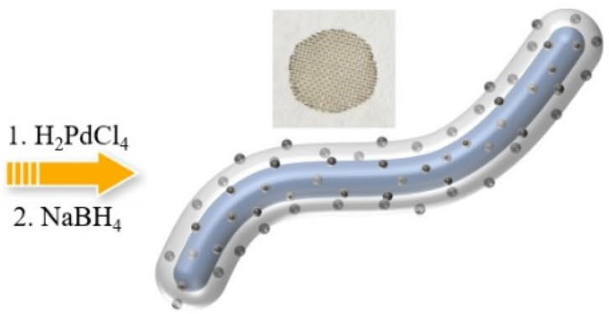

Nylon / PIM-EA-TB / Pd

Fig. 2 Illustration of the use of a Nylon substrate that is coated with PIM-EA-TB and then exposed to PdCl ${ }_{4}^{2-}$ followed by rinsing, drying, and reduction in borohydride reduction to give Pd nanoparticles embedded in the PIM-EA-TB host

\section{Instrumentation}

Clark-type polarographic dissolved oxygen probe (HI76407) and corresponding electrolyte fill solution (HI7041S) were the products of Hanna Instruments Ltd. A thin tissue layer (Whatman Schleicher \& Schuell 105 lens cleaning tissue) was introduced to maintain the distance from platinum electrode to the Teflon membrane. Ultrapure water (resistivity not less than $18.2 \mathrm{M} \Omega \mathrm{cm}$ at $20^{\circ} \mathrm{C}$ ) was taken from Thermo Scientific water purification equipment. A pH meter (Jenway 3505) was used to monitor the $\mathrm{pH}$ of buffer solutions. The morphology of the Pd@ PIM-EA-TB and Pd/Au@PIM-EA-TB nanoparticles were evaluated using a scanning electron microscope (SEM, Hitachi SU3900) and a transmission electron microscope (TEM, JEOL JEM-2100PLUS). Elemental mapping was carried out with an attached energy dispersive X-ray analyser $\left(170 \mathrm{~mm}^{2}\right.$ Ultim Max EDX). Electrochemical experiments were performed with a computer-controlled potentiostat (Metrohm microAutolab II). The quantification of $\mathrm{H}_{2} \mathrm{O}_{2}$ was carried out by liquid chromatography-mass spectroscopy (LC-MS) technique with an Agilent 6545 Accurate-Mass Q-TOF LC/MS system.

\section{Procedures}

\section{Formation of Pd@PIM-EA-TB}

A Nylon substrate was employed to investigate the catalytic activity of heterogenised catalysts. A disk of 8-mm diameter with Nylon strands of 75- $\mu \mathrm{m}$ diameter was first coated with PIM-EA-TB (approx. $20 \mu \mathrm{g}$ ). Next, the modified Nylon disk was immersed into $5 \mathrm{mM} \mathrm{PdCl}_{4}{ }^{2-}$ in $1 \mathrm{M} \mathrm{HCl}$. Under these conditions, the PIM-EA-TB is protonated and $\mathrm{PdCl}_{4}{ }^{2-}$ is accumulated into the microporous polymer which is visible as yellow coloration [35]. Next, the disks are immersed into $0.13 \mathrm{M} \mathrm{NaBH}_{4}$ solution in water and left to react in the dark in a refrigerator $\left(4^{\circ} \mathrm{C}, 20 \mathrm{~h}\right.$, see Fig. 2$)$.

Figure 3 shows scanning electron microscopy (SEM) images for the distribution of deposits on the Nylon mesh. White regions in Fig. 3A are consistent with regions of more Pd metal deposits accumulated due to a higher PIM-EA-TB loading. An enhanced presence of Pd at Nylon thread intersections is due to a higher amount of PIM-EA-TB in these regions caused capillary forces during evaporation of the deposition solution. Pd appears to be distributed in the form of uniformly sized nanoparticles (vide infra) within the PIM-EA-TB.
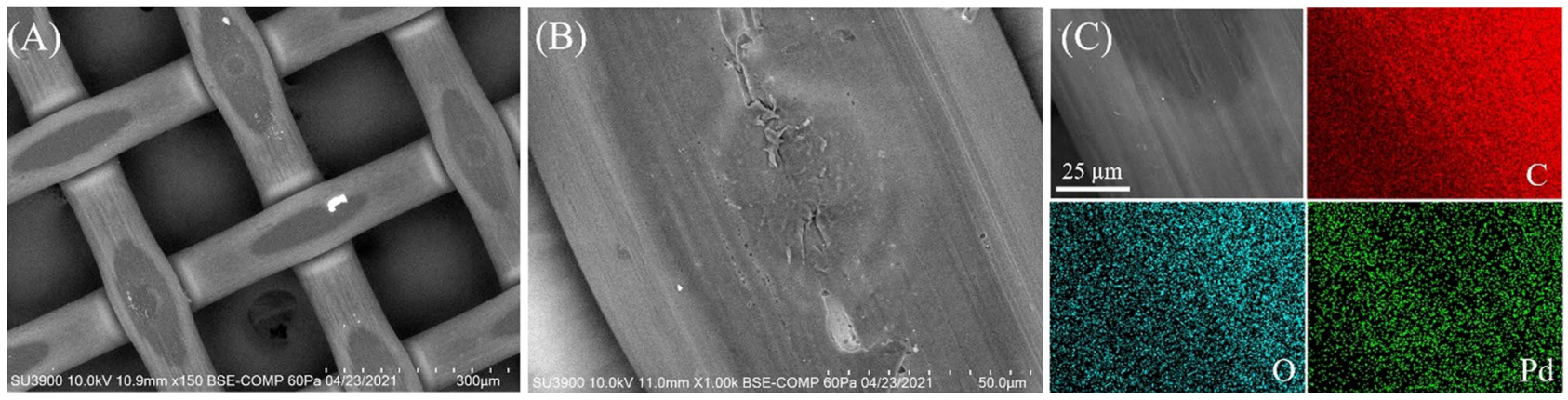

Fig. 3 Scanning electron microscopy (SEM) images A, B and energy-dispersive X-ray spectroscopy (EDX) elemental mapping analysis $\mathbf{C}$ for Pd@PIM-EA-TB coated Nylon mesh 

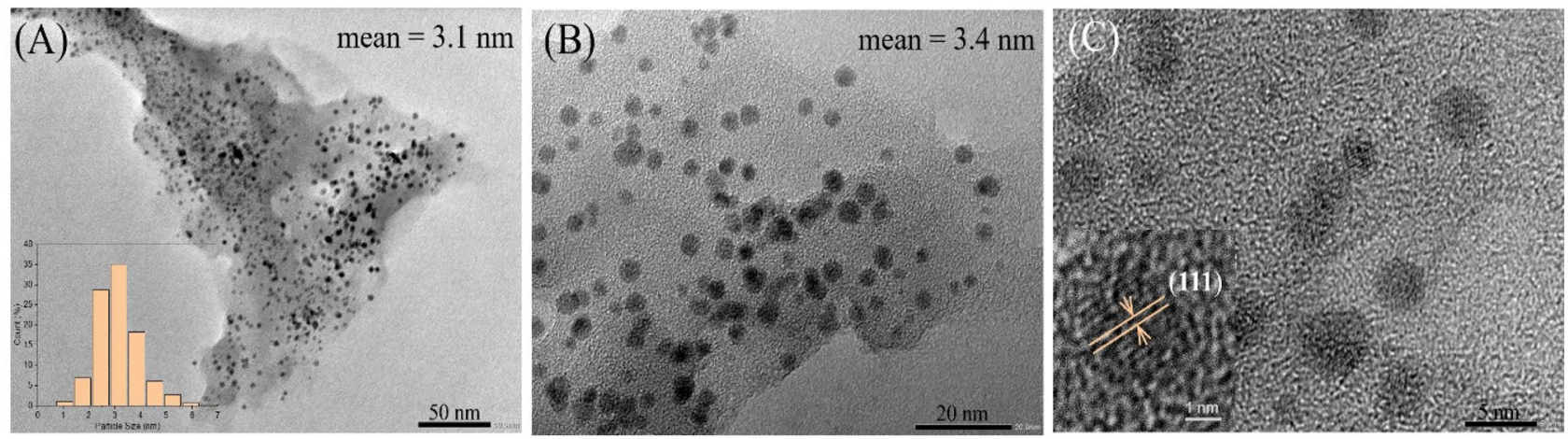

Fig. 4 Transmission electron microscopy (TEM) images for Pd@ PIM-EA-TB. A Pd nanoparticles with mean size of $3.2 \pm 0.2 \mathrm{~nm}$ evenly distributed in PIM-EA-TB (inset: size distribution of Pd nano-

In order to better image Pd nanoparticles, samples were ultrasonicated in isopropanol, and then solution phase was deposited onto transmission electron microscopy (TEM) grids. Figure 4 shows typical images for PIM-EA-TB with nanoparticles embedded. Particle size analysis suggests typically $3.2 \pm 2.0 \mathrm{~nm}$ diameter.

\section{Formation of Nano-Pd/Au@PIM-EA-TB}

The spontaneous formation of gold deposits on palladium is driven by the high $\mathrm{Au}(0 / \mathrm{III})$ standard potential driving oxygen evolution [36]. Gold deposition can be achieved by simple immersion of the Pd@PIM-EA-TB modified Nylon disks into a solution of $5 \mathrm{mM} \mathrm{KAuCl}_{4}$ in $10 \mathrm{mM}$ phosphate buffer at $\mathrm{pH} 7$ for $20 \mathrm{~h}$. Figure 5 shows SEM images and EDX analysis demonstrating the growth of gold in regions where palladium is present as nucleation site (to nucleate gold) and as water oxidation site (to drive gold deposition). particles). B Higher magnification image with mean Pd particle size of $3.4 \mathrm{~nm}$. C High-resolution image showing the (111) crystal facet of Pd

The presence of gold is confirmed in TEM images. Figure 6 shows typical regions with gold dominating over palladium. Figure 7 shows images where both gold and palladium nanoparticles can be seen side-by-side. Gold deposits are observed with typically 10 - to 35-nm diameter, often inter-grown into bigger aggregates. Visible also are some remaining palladium nanoparticles without gold modification (see Fig. 7A, B) which may affect the overall reactivity in catalytic processes (vide infra).

\section{Clark Probe Measurements}

The formation of hydrogen and the consumption of oxygen is conveniently monitored at a commercial Clark probe (Hanna Instruments Ltd.). The Nylon disk (8-mm diameter) was placed onto the Teflon membrane of the probe and fixed into place with an additional Nylon strip. Experiments with PIM-EA-TB directly coated onto the Teflon membrane were unsuccessful probably due to better diffusion through the open
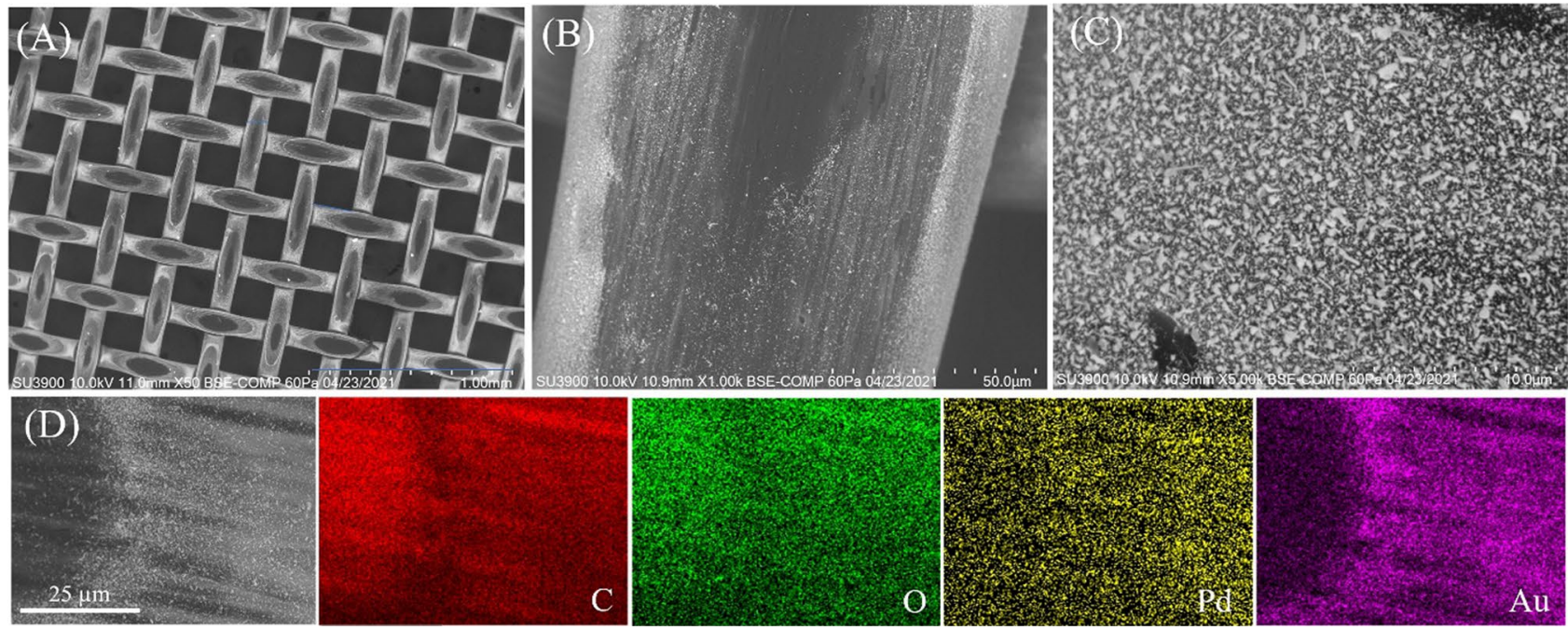

Fig. 5 SEM images with different magnifications A-C and EDX elemental mapping analysis D for Pd/Au@PIM-EA-TB coated nylon mesh 


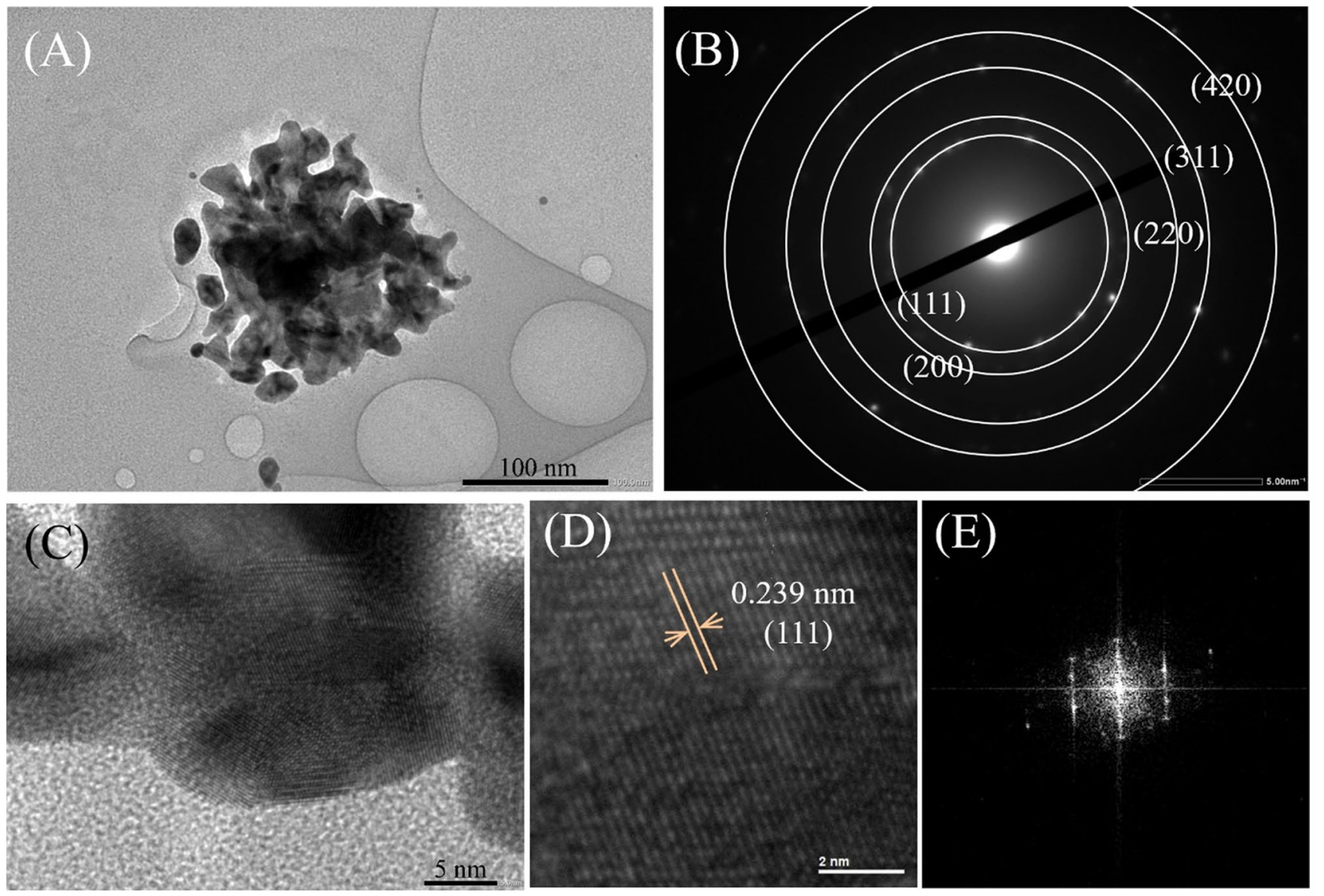

Fig. 6 TEM images for Pd/Au@PIM-EA-TB. A Au particles separated by ultrasonication. B Selected area electron diffraction (SAED) pattern with $\mathrm{Au}$ indexing. C Higher magnification of $\mathrm{Au}$ particles.

Nylon mesh (vide infra). Nylon mesh disks provide a convenient and reproducible method to explore/compare catalyst performance. Once immersed into solution, the Clark probe
D High-resolution image showing d-spacing of $0.239 \mathrm{~nm}$ indexed to (111) facet of Au. E Fast Fourier transform (FFT) diffraction patterns from $\mathbf{D}$

with Nylon disk can detect oxygen transport from the solution into the sensor or hydrogen flux from the catalyst into the sensor (monitored at different applied potentials). The

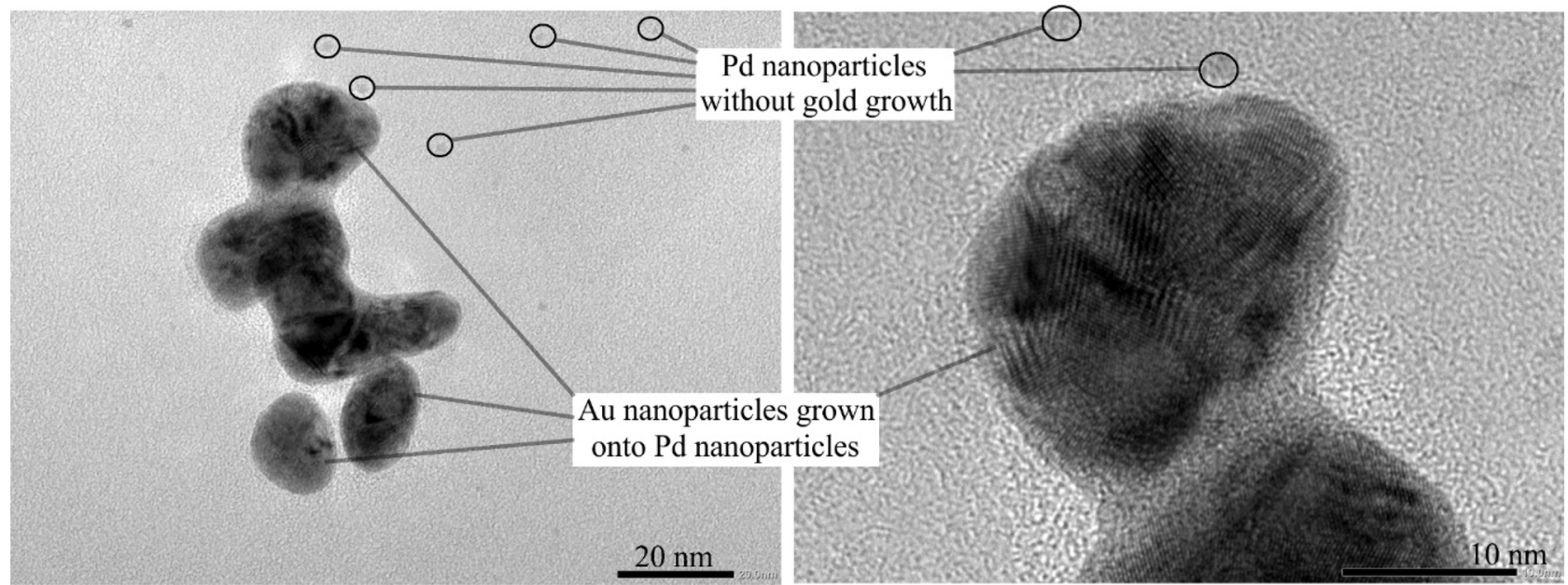

Fig. 7 TEM images for Pd/Au@PIM-EA-TB: bigger Au particles (with size of 10 to $35 \mathrm{~nm}$ intergrown into bigger aggregates) attached to small Pd nanoparticles (size of approx. $3.2 \mathrm{~nm}$ ) 
oxygen detection was performed at $-0.7 \mathrm{~V}$ vs. $\mathrm{Ag} / \mathrm{AgCl}$, and the hydrogen production was measured at $+0.6 \mathrm{~V}$ vs. $\mathrm{Ag} /$ $\mathrm{AgCl}[32,37]$.

\section{Quantification Measurement of $\mathrm{H}_{2} \mathrm{O}_{2}$ by LC-MS}

The concentration of $\mathrm{H}_{2} \mathrm{O}_{2}$ produced by catalysts was evaluated indirectly based on the reaction of para-nitrophenylboronic acid with $\mathrm{H}_{2} \mathrm{O}_{2}$ in alkaline conditions [38]. This reaction is often employed in a colorimetric assay, but here, a more powerful LC-MS analysis approach is chosen. The mechanism for formation of the para-nitrophenol product is illustrated below (Eq. 4).
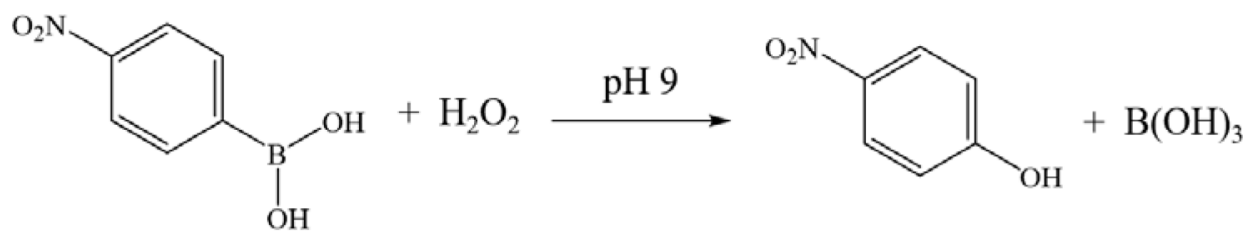

into the Clark probe). Figure 8 shows typical current-time transient data plots. Figure 8A shows the effect of formic acid on the oxygen detection. Without addition of formic acid, the Clark probe (at $-0.7 \mathrm{~V}$ vs. $\mathrm{Ag} / \mathrm{AgCl}$ ) equilibrates to about $-0.35 \mu \mathrm{A}$ after $5 \mathrm{~min}$. This corresponds to the oxygen flux from solution through the Nylon disk, through the sensor film, and to the underlying platinum sensor electrode consistent with previous reports [33]. The equilibration time (the time to quasi steady state) of 2 to $5 \mathrm{~min}$ is typical, although slower equilibration may be anticipated in the case of additional catalytic reactions at the coated Nylon disk. When adding formic acid, the oxygen signal is clearly lowered. A plot of the oxygen response versus formic acid concentration (Fig. 8B) suggests
The product para-nitrophenol is quantified by LC-MS analysis. To generate the standard calibration curve for a range of $\mathrm{H}_{2} \mathrm{O}_{2}$ concentrations, a volume of $100 \mu \mathrm{L} \mathrm{H}_{2} \mathrm{O}_{2}$ solution ranging from 2 to $500 \mu \mathrm{M}$ was mixed with $1 \mathrm{~mL}$ of $100 \mu \mathrm{M}$ para-nitrophenylboronic acid in $10 \mathrm{mM}$ carbonate buffer solution ( $\mathrm{pH} 9$ with $10 \%$ DMSO), kept in the dark for $1 \mathrm{~h}$, diluted to $1 / 50$ of the concentration with $10 \% \mathrm{DMSO} / 90 \%$ of water, and then submitted to the LC-MS analysis. For the $\mathrm{H}_{2} \mathrm{O}_{2}$ quantification in samples, the solution alkalinity was always pre-adjusted to $\mathrm{pH} 9$ by adding $\mathrm{Na}_{2} \mathrm{CO}_{3}$ powder before commencing the analysis procedure. Mass spectrometry (LC-MS) analyses were performed on an Automated Agilent QTOF (Walkup) used with HPLC (4 chromatography columns) and variable wavelength detector (Agilent QTOF 6545 with Jetstream ESI spray source coupled to an Agilent 1260 Infinity II Quat pump HPLC with 1260 autosampler, column oven compartment, and variable wavelength detector).

\section{Results and Discussion}

\section{Clark Probe Evidence for Oxygen Consumption and Hydrogen Production from Formic Acid at Pd@ PIM-EA-TB}

A Clark probe was employed with Pd@PIM-EA-TB catalyst immobilised on a Nylon mesh substrate (8-mm-diameter disks, see "Experimental"). With the Nylon substrate attached, the Clark probe allows both detection of oxygen consumption (lowering the flux of oxygen into the Clark probe) and detection of hydrogen production (inducing the flux of hydrogen that approximately half of the oxygen flux is lost for $2 \mathrm{mM}$ formic acid. For approximately $4 \mathrm{mM}$ formic acid close to all oxygen seems to be consumed locally at the catalyst.

When exploring the production of hydrogen (Fig. 8C) as a function of formic acid, a "switch-on" transition occurs at approximately $10 \mathrm{mM}$ formic acid with more formic acid leading to a plateau in the response probably linked to saturation of the solution with hydrogen. The Clark probe current (with $+0.6 \mathrm{~V}$ vs. $\mathrm{Ag} / \mathrm{AgCl}$ applied voltage) for high formic acid concentrations is consistent with the response expected when intentionally bubbling hydrogen gas to saturate the solution [33]. When purging the solution with argon gas and then adding formic acid, very similar Clark probe responses are recorded (see Fig. 8D) consistent with the observation that most oxygen is consumed by chemical reaction with $2 \mathrm{mM}$ or more formic acid.

Additional experiments with only Nylon gave no evidence of any background catalytic activity. Experiments with palladium-modified Nylon (employing the same methods but not applying PIM-EA-TB) resulted in some Pd deposit but insignificantly low activity. This suggests that the microporous PIM-EA-TB coating is crucial in (i) initially binding the $\mathrm{PdCl}_{4}{ }^{2-}$ and (ii) for allowing $\mathrm{Pd}$ nanoparticles to form embedded into the microporous PIM-EA-TB host as catalytic guests. The microporosity/microenvironment of PIMEA-TB may have additional effects on reactant and product transport. Fundamentally, net processes at the palladium catalyst can be tentatively suggested based on (Fig. 8A) oxygen consumption (processes 1 and 2, see Eqs. 1 and 2) and (Fig. 8B) based on hydrogen production (process 3, see Eq. 3, Fig. 8E). 

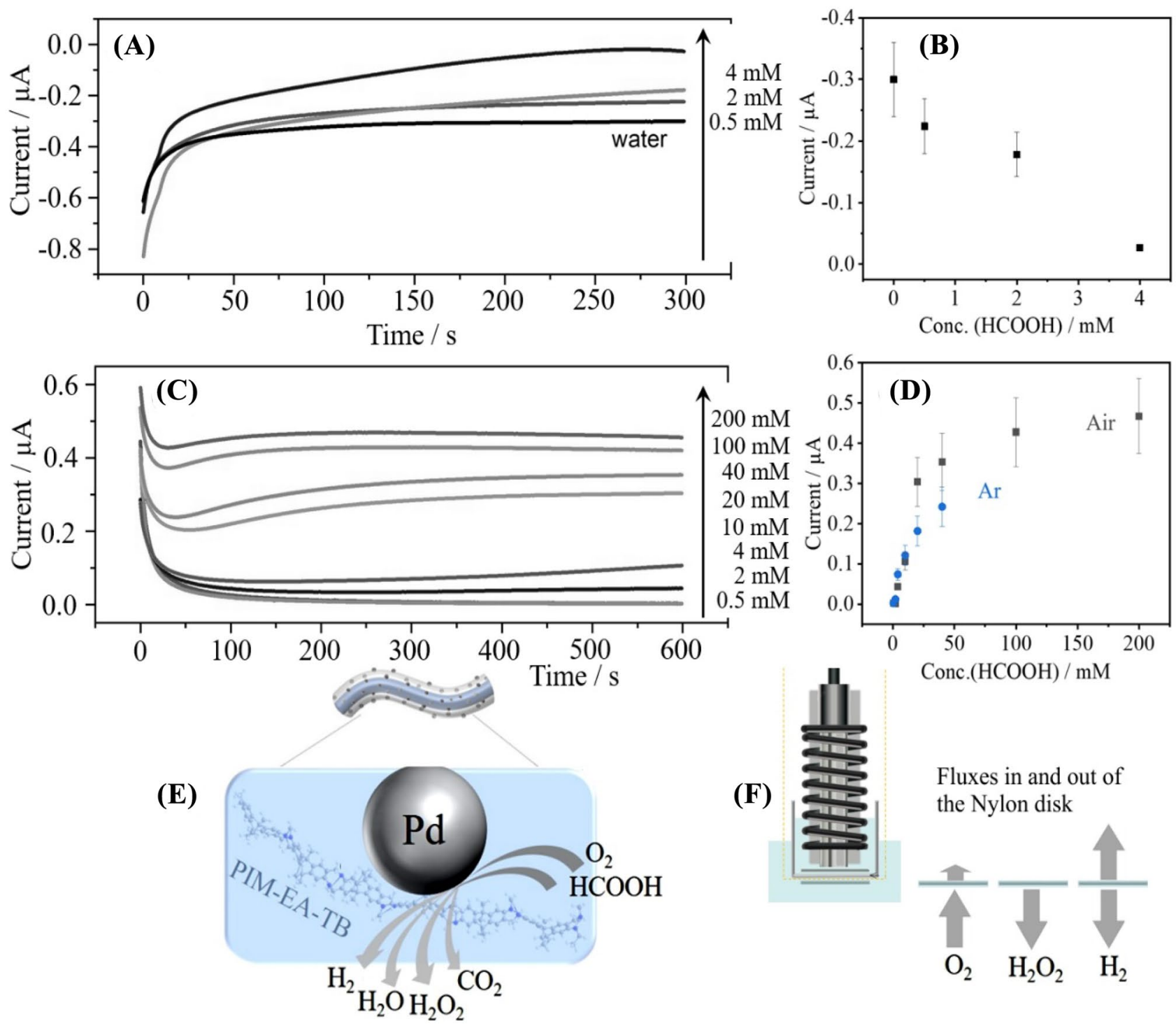

Fig. 8 A Clark probe oxygen current-time transients ( $-0.7 \mathrm{~V}$ vs. Ag/ $\mathrm{AgCl}$ applied voltage) in water, $0.5 \mathrm{mM}, 2 \mathrm{mM}$, and $4 \mathrm{mM}$ formic acid. B Plot of the approximate Clark probe oxygen responses versus formic acid concentration. C Clark probe hydrogen current-time transients (+ $0.6 \mathrm{~V}$ vs. $\mathrm{Ag} / \mathrm{AgCl}$ applied voltage) in 0.5 to $200 \mathrm{mM}$ formic

In order to discuss processes at the catalyst, it is helpful to consider fluxes to/from the Nylon disk (see Fig. 8F). The corresponding flux of oxygen into the Clark probe can be dissected and compared to the diffusion of oxygen from bulk solution and reactive flux at the catalyst. For the reactive flux density of process 1 (in $\mathrm{mol} \mathrm{m}^{-2} \mathrm{~s}^{-1}$ ), an expression rate (process 1$)=\Phi_{\text {Process } 1}=k_{1}[\mathrm{HCOOH}]\left[\mathrm{O}_{2}\right]$ can be suggested with formally $k_{1}$ (in $\mathrm{mol}^{-1} \mathrm{~m}^{4} \mathrm{~s}^{-1}$ ) representing the apparent rate constant for the surface catalytic processes within the acid. D Plot of the approximate Clark probe hydrogen response versus formic acid concentration (error bars estimated $\pm 20 \%$ ). E Schematic illustration of catalytic reactions at Pd. F Illustration of fluxes to and from the Nylon disk with catalyst

PIM-EA-TB on the Nylon substrate. The oxygen flux density (based on the same units mol m $\mathrm{m}^{-2} \mathrm{~s}^{-1}$ ), $\Phi_{\text {oxygen transport }}$ in quiescent solution can be estimated as $\Phi_{\text {oxygen transport }}=D_{\text {oxygen }}\left[\mathrm{O}_{2}\right] / \delta$ with the approximate diffusion coefficient for oxygen $D_{\text {oxygen }}=3 \times 10^{-9} \mathrm{~m}^{2} \mathrm{~s}^{-1}$ [39], the bulk concentration of oxygen typically $\left[\mathrm{O}_{2}\right]=0.2 \mathrm{~mol} \mathrm{~m}^{-3}[39]$, and the diffusion layer thickness due to natural convection in aqueous media estimated as approximately $\delta=0.5 \mathrm{~mm}$. The resulting flux density for oxygen is $\Phi_{\text {oxygen transport }}=1.2 \times 10^{-6} \mathrm{~mol} \mathrm{~m}^{-2} \mathrm{~s}^{-1}$. The case 
of equal flux densities (that is, oxygen is consumed without entering the Clark probe) was observed for $[\mathrm{HCOOH}]=4 \mathrm{mM}$, which allows the apparent rate constant for process 1 to be estimated from $\Phi_{\text {oxygen transport }} \approx \Phi_{\text {Process } 1}=k_{1}[\mathrm{HCOOH}]\left[\mathrm{O}_{2}\right]$ as $k_{1}=1.5 \times 10^{-6} \mathrm{~mol}^{-1} \mathrm{~m}^{4} \mathrm{~s}^{-1}$. This rate constant describes the consumption of oxygen under these conditions (for a given Galvani potential, vide infra) and will be discussed in more detail below.

For the production of hydrogen, the concentration at which hydrogen saturation in solution occurs at about $[\mathrm{HCOOH}]=100 \mathrm{~mol} \mathrm{~m}^{-3}$ (see Fig. 8C) can be employed to further explore reaction rates. The rate for process 3 formally is rate (process 3 ) $=k_{3}[\mathrm{HCOOH}]$ with $k_{3}$ being estimated at the point of saturation linked to the insufficient diffusion of hydrogen away from the Clark probe. The flux density for hydrogen is $\Phi_{\text {hydrogen transport }}=D_{\text {hydrogen }}\left[\mathrm{H}_{2}\right] / \delta$ with $D_{\text {hydrogen }}=9 \times 10^{-9} \mathrm{~m}^{2} \mathrm{~s}^{-1}[40]$ and $\left[\mathrm{H}_{2}\right]$ representing the saturation concentration $0.74 \mathrm{~mol} \mathrm{~m}^{-3}$. Combining the flux density for hydrogen and the formal rate equation for process 3 , rate (process 3) $=\Phi_{\text {Process 3 }}=k_{3}[\mathrm{HCOOH}]$, gives an estimate of the apparent rate constant $k_{3}=1.3 \times 10^{-7} \mathrm{~m} \mathrm{~s}^{-1}$ (under the conditions of this experiment). For $\left[\mathrm{O}_{2}\right]=0.2 \mathrm{mM}$, the flux densities $\Phi_{\text {Process } 1}$ and $\Phi_{\text {Process } 3}$ are very similar (assuming that processes 2 and 4 are valid). In order to explore/ compare, the rate for process 2 methods for $\mathrm{H}_{2} \mathrm{O}_{2}$ detection/ monitoring needs to be applied (vide infra).

When performing experiments and monitoring the evolution of hydrogen at formic acid concentration higher than $0.2 \mathrm{M}$, some deterioration of the catalyst performance can be observed upon going back to lower concentrations (not shown). There have been previous reports of palladium catalyst deterioration at higher formic acid concentrations being linked catalyst poisoning [41], but no clear mechanism has been assigned.

\section{Clark Probe Evidence for Oxygen Consumption and Hydrogen Evolution from Formic Acid at Pd/ Au@PIM-EA-TB}

When electrolessly coating the palladium catalyst with gold (see experimental), a new pattern of reactivity emerges. The modified palladium is likely to interact with formic acid in a similar manner to give $\mathrm{CO}_{2}$, protons, and electrons, but the electrons are now allowed to flow into the gold (with substantially higher surface area; see illustration in Fig. 9). Gold is known to produce hydrogen peroxide during oxygen reduction under mild conditions [42]. The $\mathrm{Pd} / \mathrm{Au}$ assembly acts as bipolar catalyst.

Figure 9A shows typical Clark probe responses (at $-0.7 \mathrm{~V}$ $v s$. $\mathrm{Ag} / \mathrm{AgCl}$ ) for oxygen removal in the presence of formic acid. The plot in Fig. 9B shows that at about $20 \mathrm{mM}$ formic acid half of the oxygen is consumed. Complete consumption of oxygen occurs at approximately $40 \mathrm{mM}$ formic acid. Formally, this suggests a process 1 rate constant $k_{1}$ an order of magnitude lower $\left(k_{1} \approx 1.5 \times 10^{-7} \mathrm{~mol}^{-1} \mathrm{~m}^{4} \mathrm{~s}^{-1}\right)$ compared to that estimated for Pd@PIM-EA-TB (see Fig. 8). The main reasons for this drop in reactivity towards oxygen consumption are the lower availability of catalytic palladium surface (although some individual palladium nanoparticles are still observed in the TEM data in Fig. 7) and a less negative Galvani potential developing on palladium/gold nanoparticle assemblies (vide infra)

Similarly, the production of hydrogen seems severely suppressed. Figure 9C shows data for hydrogen production at different formic acid concentrations. Hydrogen is clearly detected, but even with a high concentration of $1 \mathrm{M}$ formic acid, the rate of hydrogen production remains low (possibly kinetically rather than transport limited). This is consistent with significant deactivation towards hydrogen production of the palladium in Pd/Au@PIM-EA-TB. Overall, the catalyst in the presence of gold seems severely deactivated in terms of hydrogen production to approximately $1 \%$ of the activity observed without gold. In contrast, the production of hydrogen peroxide as a key intermediate in the reduction of oxygen (see process 1 ) could be enhanced under these conditions. Therefore, the production of $\mathrm{H}_{2} \mathrm{O}_{2}$ is considered next.

\section{Evidence for Hydrogen Peroxide Formation from Oxygen and Formic Acid}

In order to detect hydrogen peroxide, $\mathrm{H}_{2} \mathrm{O}_{2}$, as a product of the catalytic reaction (process 1 ), a method based on the reaction of para-nitrophenyl-boronic acid to para-nitrophenol was developed (see experimental), and the para-nitrophenol detection was performed with HPLC-MS to give a calibration range from 2 to $500 \mu \mathrm{M} \mathrm{H}_{2} \mathrm{O}_{2}$. Here, the bulk concentration of $\mathrm{H}_{2} \mathrm{O}_{2}$ is probed, and from this, the flux towards the Nylon disk is estimated. Experiments are performed in a stirred solution, and therefore, the rate of mass transport towards the catalyst is likely to be approximately 20 times higher compared to quiescent conditions at the Clark probe (assuming an order of magnitude increase in mass transport and access to both sides).

Figure 10A shows how hydrogen peroxide is produced with time. In the presence of $2 \mathrm{mM}$ formic acid and ambient oxygen levels (approx. $0.2 \mathrm{mM}$ [39]), a gradual increase (approximately linear) is observed leading to approx. $20 \mu \mathrm{M} \mathrm{H}_{2} \mathrm{O}_{2}$ after $2 \mathrm{~h}$ of reaction (for one Pd@PIM-EATB modified 8-mm diameter Nylon disk in a volume of 10 $\mathrm{cm}^{3}$ stirred solution). This is consistent with gradual transport of $\mathrm{H}_{2} \mathrm{O}_{2}$ from the Nylon disk into the bulk solution. Figure 10B shows data obtained at $2 \mathrm{~h}$ reaction time as a function of formic acid concentration (note that volume is 2 $\mathrm{cm}^{3}$ ). The point of the highest rate of $\mathrm{H}_{2} \mathrm{O}_{2}$ production with $2 \mathrm{mM}$ formic acid corresponds to $\mathrm{a}_{2} \mathrm{O}_{2}$ flux density of 

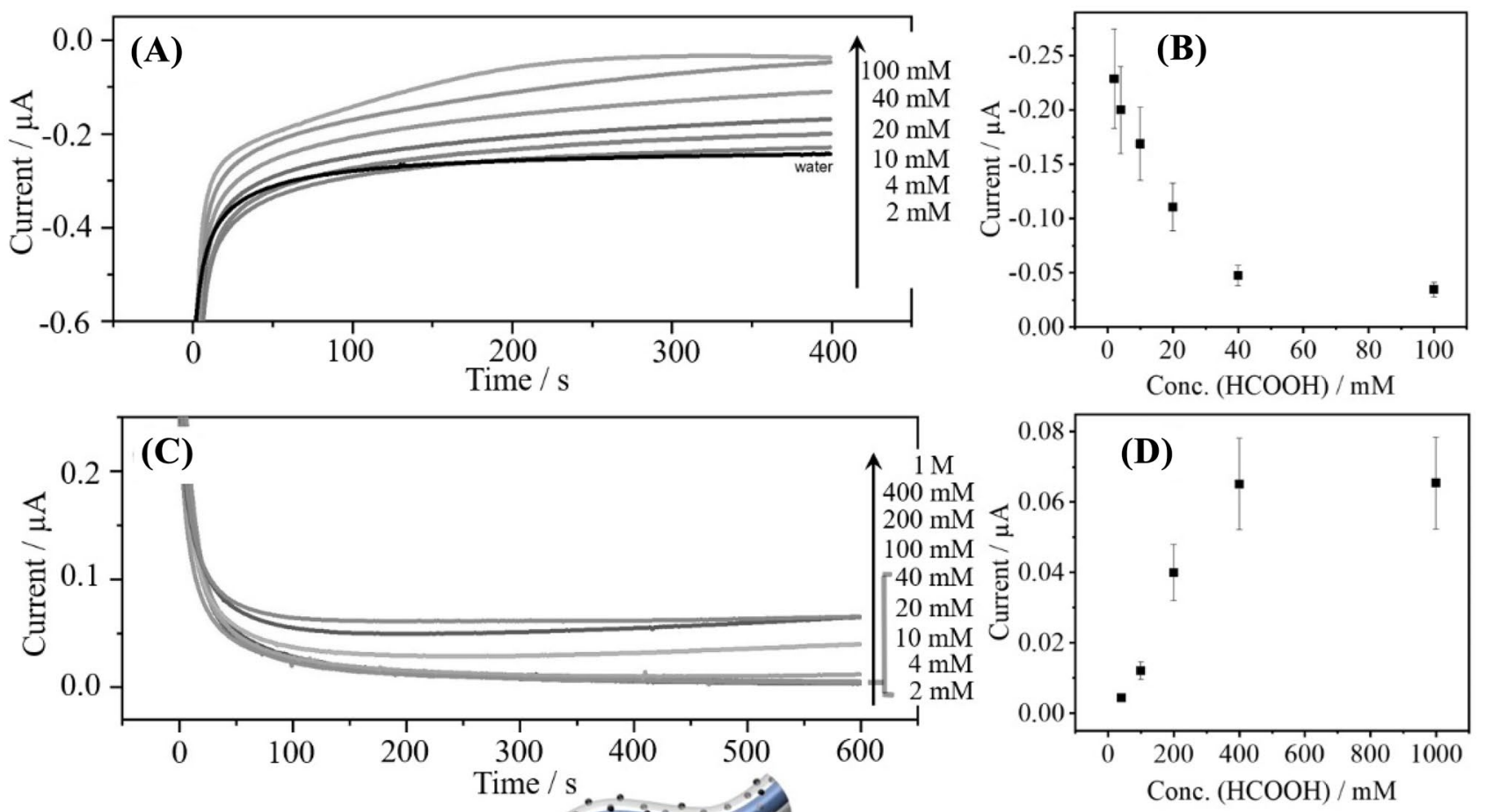

(E)

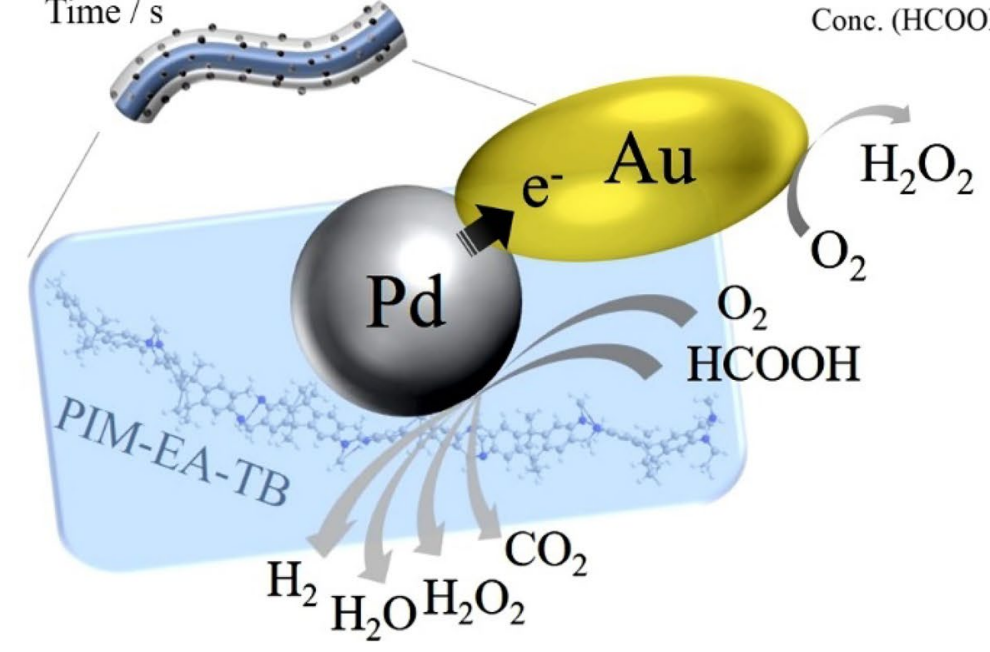

Fig. 9 A Clark probe oxygen current time transients in water, $2 \mathrm{mM}$, $4 \mathrm{mM}, 10 \mathrm{mM}, 20 \mathrm{mM}, 40 \mathrm{mM}$, and (vii) $100 \mathrm{mM}$ formic acid. B Plot of the approximate Clark probe oxygen response versus formic acid concentration (error bars estimated $\pm 20 \%$ ). C Clark probe hydro-

$\Phi_{\text {Process 1 }}=1.1 \times 10^{-7} \mathrm{~mol} \mathrm{~m}^{-2} \mathrm{~s}^{-1}$, which is very low when compared to the anticipated/estimated oxygen flux density of $\Phi_{\text {oxygen transport }}=2.4 \times 10^{-5} \mathrm{~mol} \mathrm{~m}^{-2} \mathrm{~s}^{-1}$ under these conditions (assumed 20 times higher compared to the flux to the Clark probe, vide supra). The reaction progress must be strongly affected by loss/degradation of $\mathrm{H}_{2} \mathrm{O}_{2}$ according to process 2.

In Fig. $10 \mathrm{~B}$, beyond the maximum in $\mathrm{H}_{2} \mathrm{O}_{2}$ production at $2 \mathrm{mM}$ formic acid the yield of $\mathrm{H}_{2} \mathrm{O}_{2}$ decreases again. This can be explained based on the ability of $\mathrm{Pd}$ nanoparticles to reduce $\mathrm{H}_{2} \mathrm{O}_{2}$ to $\mathrm{H}_{2} \mathrm{O}$. The data are consistent with sufficient flux of oxygen towards the Nylon disk, where locally (in the gen current time transients in 2 to $1000 \mathrm{mM}$ formic acid. D Plot of the approximate Clark probe hydrogen response versus formic acid concentration (error bars estimated $+/-20 \%$ ). E Schematic illustration (not to scale) of catalytic reactions at $\mathrm{Pd} / \mathrm{Au}$

PIM-EA-TB), the increase in the formic acid concentration from 2 to $4 \mathrm{mM}$ causes more reduction of $\mathrm{H}_{2} \mathrm{O}_{2}$ to $\mathrm{H}_{2} \mathrm{O}$ (vide supra).

Figure 10C shows data for the production of $\mathrm{H}_{2} \mathrm{O}_{2}$ with time for Pd/Au@PIM-EA-TB catalyst. In this case, $10 \mathrm{mM}$ formic acid was employed to drive the process. When compared to data in Fig. 10A, the rate of $\mathrm{H}_{2} \mathrm{O}_{2}$ production seems approximately 5-times higher consistent with the 5-times higher concentration of formic acid. Figure 10D shows the $\mathrm{H}_{2} \mathrm{O}_{2}$ yield at 2-h reaction time as a function of formic acid concentration. In the presence of gold, an order of magnitude increase in $\mathrm{H}_{2} \mathrm{O}_{2}$ yields is evident. From this, the 

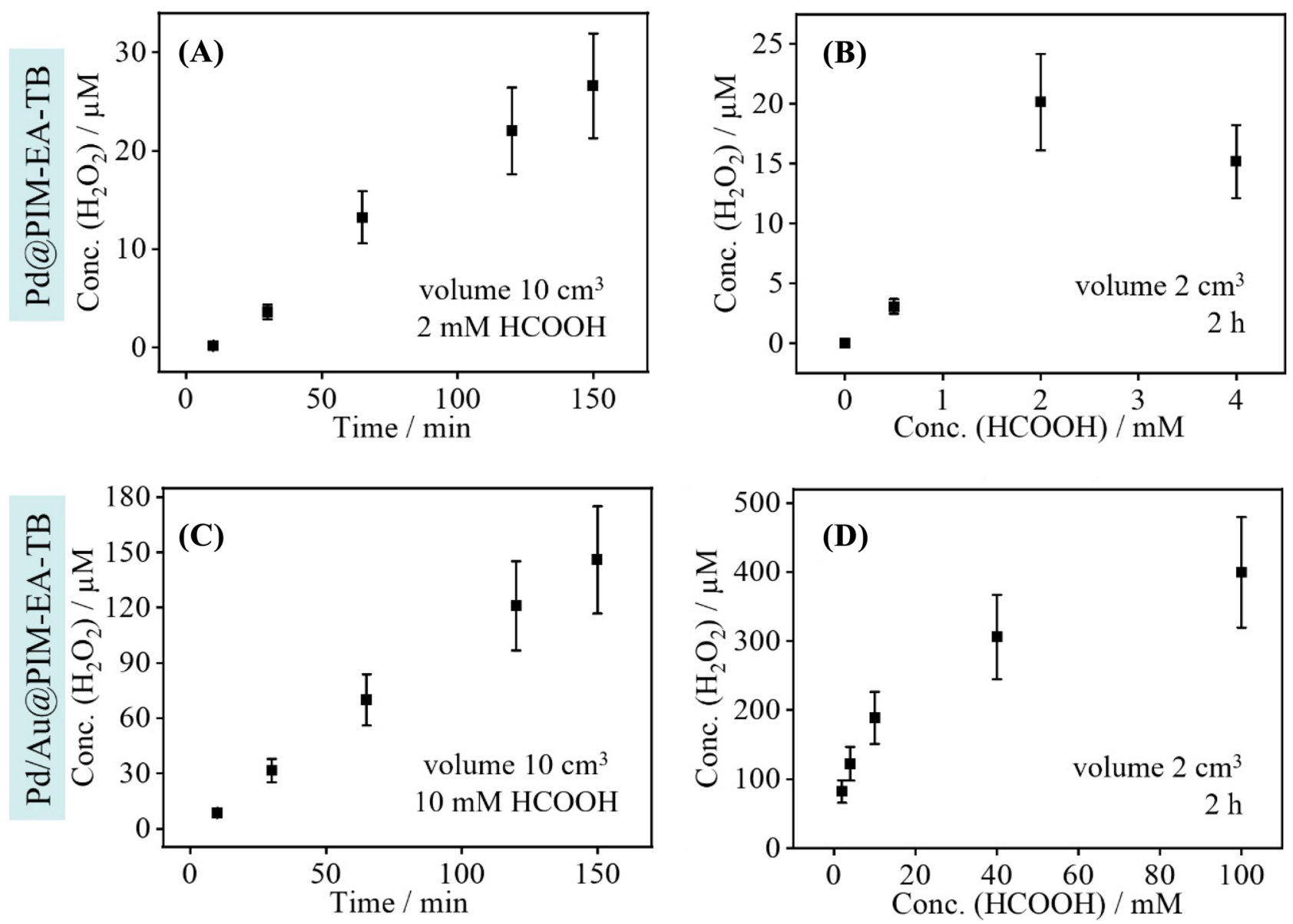

Fig. 10 A Plot of $\mathrm{H}_{2} \mathrm{O}_{2}$ concentration as a function of time (one Nylon disk modified with Pd@PIM-EA-TB in $10 \mathrm{~mL}$ stirred solution) for $2 \mathrm{mM}$ formic acid concentration. B Plot of $\mathrm{H}_{2} \mathrm{O}_{2}$ concentration after 120-min reaction (one nylon disk modified with Pd@PIM-EATB in $2 \mathrm{~mL}$ stirred solution) as a function of formic acid concentration. C Plot of $\mathrm{H}_{2} \mathrm{O}_{2}$ concentration as a function of time (one Nylon

approximate $\mathrm{H}_{2} \mathrm{O}_{2}$ flux density at the Nylon disk can be calculated as $\Phi_{\text {Process } 1}=1.0 \times 10^{-7} \mathrm{~mol} \mathrm{~m}^{-2} \mathrm{~s}^{-1}$ in the presence of $10 \mathrm{mM}$ formic acid. The production of $\mathrm{H}_{2} \mathrm{O}_{2}$ further increases with formic acid concentration (see Fig. 10D) and, finally, plateaus at high formic acid concentration with $\Phi_{\text {Process 1 }}=2.2 \times 10^{-7} \mathrm{~mol} \mathrm{~m}^{-2} \mathrm{~s}^{-1}$. This value is still low when compared to the anticipated oxygen flux, and therefore, oxygen transport is unlikely to significantly affect the production of $\mathrm{H}_{2} \mathrm{O}_{2}$. Under conditions of high formic acid concentration, a plateau suggests that a steady state is approached and that the process becomes independent of $[\mathrm{HCOOH}]$. Combining the rate expressions for process 1 and process 2 (Eqs. 2 and 3 ) for the case of high $[\mathrm{HCOOH}]$ suggests that $k_{1} / k_{2}=\left[\mathrm{H}_{2} \mathrm{O}_{2}\right] /\left[\mathrm{O}_{2}\right]$. With $k_{1}=1.5 \times 10^{-6} \mathrm{~mol}^{-1}$ $\mathrm{m}^{4} \mathrm{~s}^{-1}$ and $\left[\mathrm{H}_{2} \mathrm{O}_{2}\right]=0.4 \mathrm{mM}$ and $\left[\mathrm{O}_{2}\right]=0.2 \mathrm{mM}$, this gives an apparent rate constant $k_{2}=1 / 2 k_{1}=0.75 \times 10^{-7} \mathrm{~mol}^{-1}$ $\mathrm{m}^{4} \mathrm{~s}^{-1}$ for the case of Pd/Au@PIM-EA-TB. Although disk modified with Pd/Au@PIM-EA-TB in $10 \mathrm{~mL}$ stirred solution) for $10 \mathrm{mM}$ formic acid concentration. D Plot of $\mathrm{H}_{2} \mathrm{O}_{2}$ concentration after 120-min reaction (one Nylon disk modified with Pd/Au@PIMEA-TB in $2 \mathrm{~mL}$ stirred solution) as a function of formic acid concentration (error bars based on variations in catalyst disks and Clark probe responses estimated $\pm 20 \%$ )

the production of $\mathrm{H}_{2} \mathrm{O}_{2}$ is significant, it could be further improved for example based on the oxygen available in solution

It is interesting to further explore the reactivity of $\mathrm{Pd} /$ Au@PIM-EA-TB for the production of hydrogen peroxide. Figure 11A shows data for the effect of doubling the amount of catalyst (using one Nylon disk and using two Nylon disks in a stirred solution). Perhaps surprisingly, only at short times (for low $\left[\mathrm{H}_{2} \mathrm{O}_{2}\right]$ ), the production of $\mathrm{H}_{2} \mathrm{O}_{2}$ is enhanced. For $1 \mathrm{~h}$ or longer reaction times, the effect of increasing the amount of catalyst seems insignificant. A change in the amount of catalyst will affect the apparent rate constants $k_{1}$ and $k_{2}$, but not the long-term steady state concentration of $\mathrm{H}_{2} \mathrm{O}_{2}$ that is given by the ratio of $k_{1} / k_{2}$. That is, for longer periods of reaction or for higher formic acid concentrations, the same limiting concentration $\left[\mathrm{H}_{2} \mathrm{O}_{2}\right]_{\text {lim }}$ is generated independently of the amount of catalyst. 

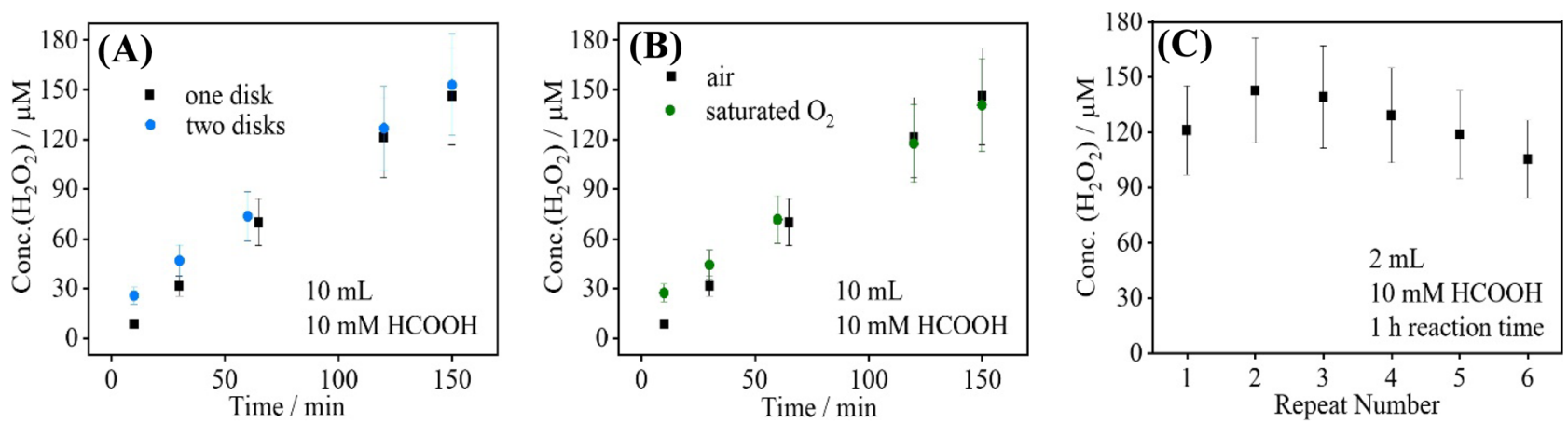

Fig. 11 A Plot of $\mathrm{H}_{2} \mathrm{O}_{2}$ concentration formed at $\mathrm{Pd} / \mathrm{Au} @$ PIM-EA$\mathrm{TB}$ in the presence of $10 \mathrm{mM}$ formic acid as a function of time. Data sets for (i) one Nylon disk and (ii) two Nylon disks modified with $\mathrm{Pd} / \mathrm{Au} @$ PIM-EA-TB in $10 \mathrm{~cm}^{3}$ stirred solution. B Plot of $\mathrm{H}_{2} \mathrm{O}_{2}$ concentration formed at Pd/Au@PIM-EA-TB in the presence of $10 \mathrm{mM}$ formic acid as a function of time. Data sets for (i) $0.2 \mathrm{mM}$ oxygen and (ii) $1 \mathrm{mM}$ oxygen for one Nylon disk modified with Pd/Au@

Figure 11B demonstrates the effect of changing the concentration of oxygen from ambient (approx. $0.2 \mathrm{mM}$ ) to saturated (approx. $1.0 \mathrm{mM}$ ). The data suggest a significant increase in $\mathrm{H}_{2} \mathrm{O}_{2}$ production only during the initial $30 \mathrm{~min}$, and a value converging with time. The final value $\left[\mathrm{H}_{2} \mathrm{O}_{2}\right]_{\text {lim }}$ obtained in the presence of saturated $\left[\mathrm{O}_{2}\right]$ could be increased, but the data recorded over a period of $150 \mathrm{~min}$ suggests a very similar trend. Finally, Fig. $11 \mathrm{C}$ shows that the re-use of the catalyst-modified Nylon disks is possible. For $10 \mathrm{mM}$ formic acid, the production of hydrogen peroxide remains approximately constant in 6 sequential experiments producing $\mathrm{H}_{2} \mathrm{O}_{2}$ each over a period of $1 \mathrm{~h}$
PIM-EA-TB in $10 \mathrm{~cm}^{3}$ stirred solution. C Plot of $\mathrm{H}_{2} \mathrm{O}_{2}$ concentration formed at Pd/Au@PIM-EA-TB in the presence of $10 \mathrm{mM}$ formic acid at $1 \mathrm{~h}$ reaction time for repeat experiments (one Nylon disk modified with Pd/Au@PIM-EA-TB in $2 \mathrm{~cm}^{3}$ stirred solution) (error bars based on variations in catalyst disks and Clark probe responses estimated $\pm 20 \%$ )

The catalytic production of $\mathrm{H}_{2} \mathrm{O}_{2}$ on a bipolar Pd/Au nanocatalyst can be discussed in terms of individual redox processes and assuming Tafel law effects on kinetics linked to the Galvani potential of the catalyst particles. That is, apparent rate constants observed under specific reaction conditions are variable with potential similar to heterogeneous charge transfer rate constants. The scheme in Fig. 12A illustrates the case of formic acid spontaneously producing hydrogen and then hydrogen being oxidised to protons. The rate for this process is Galvani potential dependent (assumed here to follow Tafel characteristics) and indicated as a line. The oxidation is faster at higher potentials. Also indicated is the line for the reduction

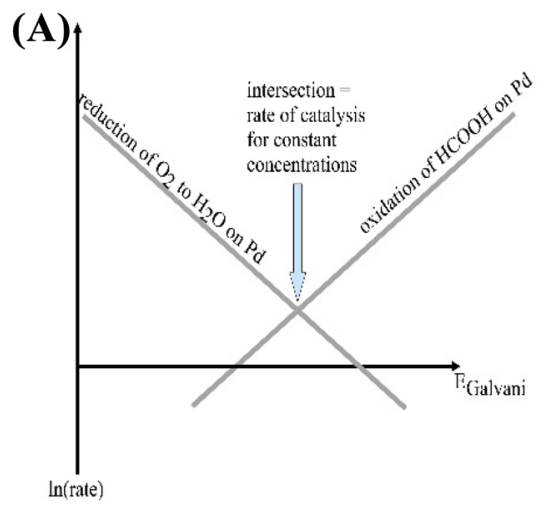

Fig. 12 Schematic illustration of the effect of the Galvani potential on the reaction rate. A Oxidation of formic acid and reduction of oxygen leads to a mixed potential on Pd. B On Pd oxidation of formic acid and reduction of oxygen form mixed potential (1) and after depletion
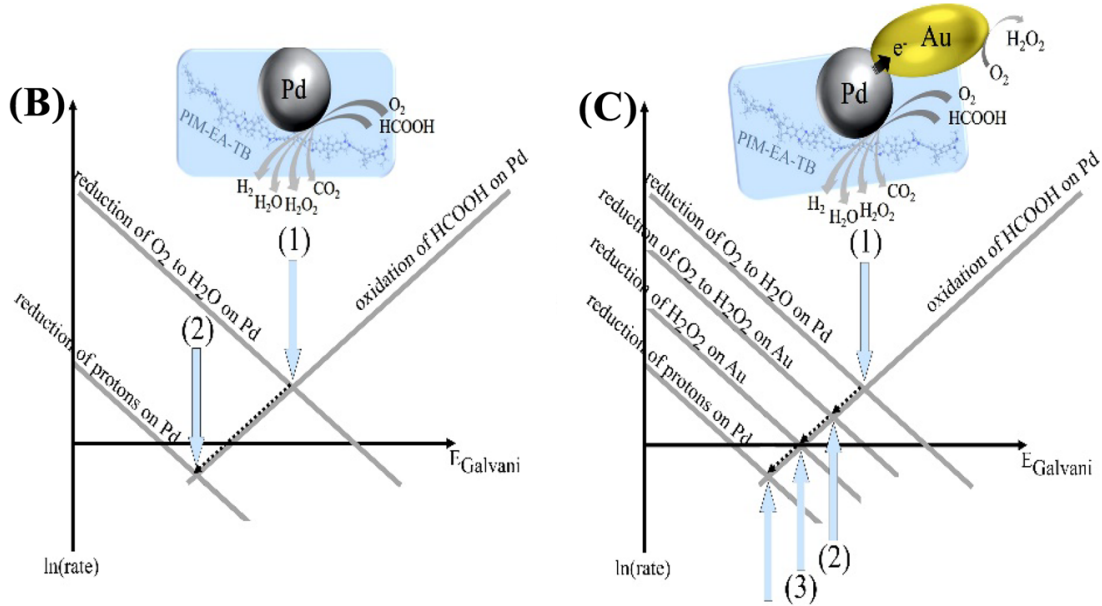

(4) of oxygen the potential shifts to (2). C On Pd/Au oxidation of formic acid on Pd leads to a mixed potential for reduction of $\mathrm{O}_{2}$ on $\mathrm{Pd}(1)$, then reduction of $\mathrm{O}_{2}$ to $\mathrm{H}_{2} \mathrm{O}_{2}$ on $\mathrm{Au}(2)$, then reduction of $\mathrm{H}_{2} \mathrm{O}_{2}$ on $\mathrm{Au}$ (3), and, finally, reduction of protons to hydrogen (4) 
of oxygen to water. The point of intersection denotes the operational potential during catalysis at a given concentration of reagents. Figure 12B illustrates the effect of oxygen depletion. Due to oxygen being consumed, the rate for the oxygen reduction slows down and the intersection point (1) moves along the line to point (2). Point (2) corresponds to the equilibrium potential for $\mathrm{H}^{+} / \mathrm{H}_{2}$ at more negative potentials.

The case for the bipolar $\mathrm{Pd} / \mathrm{Au}$ catalyst is illustrated in Fig. 12C. Initially, the catalyst operates at potential (1) where oxygen is reduced on Pd mainly to water. Depletion of oxygen then shifts the potential to point (2) where oxygen is reduced to $\mathrm{H}_{2} \mathrm{O}_{2}$ on $\mathrm{Au}$. This corresponds to the optimum working conditions for the bipolar catalyst with further depletion of oxygen pushing the Galvani potential more negative where $\mathrm{H}_{2} \mathrm{O}_{2}$ is consumed again (3). For a good conversion of oxygen to $\mathrm{H}_{2} \mathrm{O}_{2}$ (i), the process at point (1) needs to be suppressed by adjusting the ratio of Pd to Au surface area, (i) the process at point (2) needs to be optimised by providing a high Au surface area, and (iii) the concentration of formic acid has to be selected to maintain the operational potential of the bipolar catalysts close to (2).

The polymer of intrinsic microporosity is likely to affect locally the mass transport of formic acid, oxygen, and hydrogen peroxide and is therefore also likely to affect $\mathrm{H}_{2} \mathrm{O}_{2}$ yields. Further work is required to explore effects for different types of polymers of intrinsic microporosity on these catalytic processes. The yields for $\mathrm{H}_{2} \mathrm{O}_{2}$ observed in this study are modest and should be much higher with more optimisation. Recent progress in the catalytic production of $\mathrm{H}_{2} \mathrm{O}_{2}$ directly from $\mathrm{H}_{2}$ and $\mathrm{O}_{2}$ gas at $\mathrm{PdAu}$ alloy catalysts suggests that up to $56 \mathrm{mM}$ $\mathrm{H}_{2} \mathrm{O}_{2}$ in water can be achieved [43]. This is two orders of magnitude higher compared to yields reported here. Clearly, more work will be necessary to compare/improve reactivity, to optimise conditions, and to resolve/exploit PIM host effects in this process in the future.

\section{Conclusions}

It has been shown that both nano-Pd and nano-Pd/Au catalysts can be formed embedded inside of the microporous host polymer PIM-EA-TB. In the presence of formic acid, both types of catalyst were shown with a Clark probe to consume oxygen and to produce hydrogen. Pd is effective in producing hydrogen, whereas $\mathrm{Pd} / \mathrm{Au}$ appears to be ineffective. High concentrations of formic acid can be detrimental and may deactivate the catalysts.

In the formic acid concentration range where oxygen consumption and hydrogen production switch over (as observed with the Clark probe), maximum hydrogen peroxide production rates were observed. In contrast to nano$\mathrm{Pd}$, bipolar nano-Pd/Au catalysts clearly produce higher levels of hydrogen peroxide with only minimal production of hydrogen even at high formic acid concentrations. This has been attributed to electron transport from $\mathrm{Pd}$ to $\mathrm{Au}$ and a less negative Galvani potential on the nano-Pd/Au catalyst during operation. Formic acid reacts on Pd followed by electron transfer to gold. On gold, oxygen is reduced primarily to $\mathrm{H}_{2} \mathrm{O}_{2}$.

The role of the intrinsically microporous polymer, PIM-EA-TB, in these catalytic reactions is associated with (i) providing a reaction environment for binding $\mathrm{Pd}(\mathrm{II})$ and for producing embedded palladium nanoparticles, (ii) for allowing the growth of gold nanoparticles attached to palladium seeds, (iii) for permeation of reactants and products, and (iv) for making the catalysts recoverable and re-usable. The tertiary amine functional group in PIM-EA-TB is essential for the initial binding of $\mathrm{PdCl}_{4}{ }^{2-}$ but could have additional effects on the catalytic process, for example when binding or permeating reaction intermediates. In the future, the molecular structure of PIM-EA-TB could be modified or tuned to allow better/more selective catalytic processes to be developed. For further optimisation of $\mathrm{H}_{2} \mathrm{O}_{2}$ production from organic reducing agents such as formic acid, the suppression of $\mathrm{H}_{2} \mathrm{O}_{2}$ degradation (process 2) appears to be crucial and this could be achieved for example by adjusting the ratio of Pd to Au surface area.

Funding L.W. received a $\mathrm{PhD}$ stipend from the China Scholarship Council (201906870022). F.M. received support under project EP/ K004956/1 from the EPSRC.

Open Access This article is licensed under a Creative Commons Attribution 4.0 International License, which permits use, sharing, adaptation, distribution and reproduction in any medium or format, as long as you give appropriate credit to the original author(s) and the source, provide a link to the Creative Commons licence, and indicate if changes were made. The images or other third party material in this article are included in the article's Creative Commons licence, unless indicated otherwise in a credit line to the material. If material is not included in the article's Creative Commons licence and your intended use is not permitted by statutory regulation or exceeds the permitted use, you will need to obtain permission directly from the copyright holder. To view a copy of this licence, visit http://creativecommons.org/licenses/by/4.0/.

\section{References}

1. R. Tao, X.R. Ma, X.L. Wei, Y.H. Jin, L. Qiu, W. Zhang, Porous organic polymer material supported palladium nanoparticles. J. Mater. Chem. A 8(34), 17360-17391 (2020)

2. F.X. Felpin, T. Ayad, S. Mitra, Pd/C: an old catalyst for new applications - its use for the Suzuki-Miyaura reaction. Europ. J. Org. Chem. 2006(12), 2679-2690 (2006)

3. A.R. Bayguzina, R.I. Khusnutdinov, Catalytic N-alkylation of anilines. Russ. J. Gen. Chem. 91(3), 305-347 (2021) 
4. F. Menegazzo, M. Signoretto, E. Ghedini, G. Strukul, Looking for the "dream catalyst" for hydrogen peroxide production from hydrogen and oxygen. Catalysis 9(3), 251 (2019)

5. R. Dittmeyer, J.D. Grunwaldt, A. Pashkova, A review of catalyst performance and novel reaction engineering concepts in direct synthesis of hydrogen peroxide. Catal. Today 248, 149-159 (2015)

6. N. Dimitratos, J.A. Lopez-Sanchez, G.J. Hutchings, Green catalysis with alternative feedstocks. Topics Catalysis 52(3), 258-268 (2009)

7. M.J. Zhong, Y.S. Xu, J. Li, Z.X. Ge, C.M. Jia, Y. Chen, P.L. Deng, X.L. Tian, Engineering PdAu nanowires for highly efficient direct methane conversion to methanol under mild conditions. J. Phys. Chem. C 125(23), 12713-12720 (2021)

8. I. Saldan, Y. Semenyuk, I. Marchuk, O. Reshetnyak, Chemical synthesis and application of palladium nanoparticles. J. Mater. Sci. 50(6), 2337-2354 (2015)

9. H. Zhong, M. Iguchi, M. Chatterjee, Y. Himeda, Q. Xu, H. Kawanami, Formic acid-based liquid organic hydrogen carrier system with heterogeneous catalysts. Adv. Sustain. Systems 2(2), 1700161 (2018)

10. M.C. Luo, Y. Yang, Y.J. Sun, Y.N. Qin, C.J. Li, Y.J. Li, M.G. Li, S. Zhang, D. Su, S.J. Guo, Ultrathin two-dimensional metallic nanocrystals for renewable energy electrocatalysis. Mater. Today 23, 45-56 (2019)

11. S.M.S. Hussain, M.S. Kamal, M.K. Hossain, Recent developments in nanostructured palladium and other metal catalysts for organic transformation. J. Nanomater. 2019, 1562130 (2019)

12. K. Halder, G. Bengtson, V. Filiz, V. Abetz, Catalytically active (Pd) nanoparticles supported by electrospun PIM-1: influence of the sorption capacity of the polymer tested in the reduction of some aromatic nitro compounds. Appl. Catal. A-Gen. 555, 178-188 (2018)

13. H.R. Moon, D.W. Lim, M.P. Suh, Fabrication of metal nanoparticles in metal-organic frameworks. Chem. Soc. Rev. 42, 18071824 (2013)

14. Z.X. Low, P.M. Budd, N.B. McKeown, D.A. Patterson, Gas permeation properties, physical aging, and its mitigation in high free volume glassy polymers. Chem. Rev. 118, 5871-5911 (2018)

15. N.B. McKeown, P.M. Budd, Polymers of intrinsic microporosity (PIMs): organic materials for membrane separations, heterogeneous catalysis and hydrogen storage. Chem. Soc. Rev. 35, 675-683 (2006)

16. L.N. Wang, Y.Z. Zhao, B.B. Fan, M. Carta, R. Malpass-Evans, N.B. McKeown, F. Marken, Polymer of intrinsic microporosity (PIM) films and membranes in electrochemical energy storage and conversion: a mini-review. Electrochem. Commun. 118, 106798 (2020)

17. F. Marken, E. Madrid, Y.Z. Zhao, M. Carta, N.B. McKeown, Polymers of intrinsic microporosity in triphasic electrochemistry: perspectives. ChemElectroChem 6, 4332-4342 (2019)

18. S.D. Ahn, A. Kolodziej, R. Malpass-Evans, M. Carta, N.B. McKeown, S.D. Bull, A. Buchard, F. Marken, Polymer of intrinsic microporosity induces host-guest substrate selectivity in heterogeneous 4-benzoyloxy-TEMPO-catalysed alcohol oxidations. Electrocatalysis 7, 70-78 (2016)

19. Y.Z. Zhao, N.A. Al Abass, R. Malpass-Evans, M. Carta, N.B. McKeown, E. Madrid, P.J. Fletcher, F. Marken, Photoelectrochemistry of immobilised Pt@g- $\mathrm{C}_{3} \mathrm{~N}_{4}$ mediated by hydrogen and enhanced by a polymer of intrinsic microporosity PIM-1. Electrochem. Commun. 103, 1-6 (2019)

20. D.P. He, D.S. He, J.L. Yang, Z.X. Low, R. Malpass-Evans, M. Carta, N.B. McKeown, F. Marken, Molecularly rigid microporous polyamine captures and stabilizes conducting platinum nanoparticle networks. ACS Appl. Mater. Interfaces 8, 2242522430 (2016)
21. R.K. Adamik, N. Hernandez-Ibanez, J. Iniesta, J.K. Edwards, A.G.R. Howe, R.D. Armstrong, S.H. Taylor, A. Roldan, Y.Y. Rong, R. Malpass-Evans, M. Carta, N.B. McKeown, D.P. He, F. Marken, Platinum nanoparticle inclusion into a carbonized polymer of intrinsic microporosity: electrochemical characteristics of a catalyst for electroless hydrogen peroxide production. Nanomaterials 8, 542 (2018)

22. E. Madrid, Y.Y. Rong, M. Carta, N.B. McKeown, R. MalpassEvans, G.A. Attard, T.J. Clarke, S.H. Taylor, Y.T. Long, F. Marken, Metastable ionic diodes derived from an amine-based polymer of intrinsic microporosity. Angew. Chem. Inter. Ed. 53, 10751-10754 (2014)

23. Y.Y. Rong, A. Kolodziej, E. Madrid, M. Carta, R. Malpass-Evans, N.B. McKeown, F. Marken, Polymers of intrinsic microporosity in electrochemistry: anion uptake and transport effects in thin film electrodes and in free-standing ionic diode membranes. J. Electroanal. Chem. 779, 241-249 (2016)

24. Y. Liu, X.K. Zeng, X.Y. Hu, Y. Xia, X.W. Zhang, Solar-driven photocatalytic disinfection over 2D semiconductors: the generation and effects of reactive oxygen species. Solar RRL 5, 2000594 (2021)

25. N. Dimitratos, J.A. Lopez-Sanchez, G.J. Hutchings, Green catalysis with alternative feedstocks. Topics Catal. 52, 258-268 (2009)

26. P.N.R. Vennestrom, C.H. Christensen, S. Pedersen, J.D. Grunwaldt, J.M. Woodley, Next-generation catalysis for renewables: combining enzymatic with inorganic heterogeneous catalysis for bulk chemical production. ChemCatChem 2, 249-258 (2010)

27. J.S. Hu, P.F. Zhang, W.J. An, L. Liu, Y.H. Liang, W.Q. Cui, In-situ Fe-doped g- $\mathrm{C}_{3} \mathrm{~N}_{4}$ heterogeneous catalyst via photocatalysis-Fenton reaction with enriched photocatalytic performance for removal of complex wastewater. Appl. Catal. B Environm. 245, 130-142 (2019)

28. B.M. Choudary, M.L. Kantam, P.L. Santhi, New and ecofriendly options for the production of speciality and fine chemicals. Catal. Today 57, 17-32 (2000)

29. J.J. Gao, B. Liu, Progress of electrochemical hydrogen peroxide synthesis over single atom catalysts. ACS Mater. Lett. 2, 1008$1024(2020)$

30. A. Torres-Pinto, M.J. Sampaio, C.G. Silva, J.L. Faria, A.M.T. Silva, Recent strategies for hydrogen peroxide production by metal-free carbon nitride photocatalysts. Catalysis 9, 990 (2019)

31. hydrogen peroxide as intermediate and reagent, M. Comotti, C. Della Pina, E. Falletta, M. Rossi, Aerobic oxidation of glucose with gold catalyst. Adv. Synth. Catal. 348, 313-316 (2006)

32. M.S. Yalfani, S. Contreras, F. Medina, J. Sueiras, Direct generation of hydrogen peroxide from formic acid and $\mathrm{O}_{2}$ using heterogeneous $\mathrm{Pd} / \mathrm{gamma}-\mathrm{Al}_{2} \mathrm{O}_{3}$ catalysts. Chem. Commun. 3885-3887, 8 (2008)

33. Y.Z. Zhao, R. Malpass-Evans, M. Carta, N.B. McKeown, P.J. Fletcher, G. Kociok-Kohn, D. Lednitzky, F. Marken, Size-selective photoelectrochemical reactions in microporous environments: clark probe investigation of $\mathrm{Pt} @ \mathrm{~g}-\mathrm{C}_{3} \mathrm{~N}_{4}$ embedded into intrinsically microporous polymer (PIM-1). ChemElectroChem (2021). https:// doi.org/10.1002/celc.202100732

34. M. Carta, R. Malpass-Evans, M. Croad, Y. Rogan, J.C. Jansen, P. Bernardo, F. Bazzarelli, N.B. McKeown, An efficient polymer molecular sieve for membrane gas separations. Science $\mathbf{3 3 9}$, 303-307 (2013)

35. F.J. Xia, M. Pan, S.C. Mu, R. Malpass-Evans, M. Carta, N.B. McKeown, G.A. Attard, A. Brew, D.J. Morgan, F. Marken, Polymers of intrinsic microporosity in electrocatalysis: novel pore rigidity effects and lamella palladium growth. Electrochim. Acta 128, 3-9 (2014)

36. T. Kanyanee, P.J. Fletcher, E. Madrid, F. Marken, Indirect (hydrogendriven) electrodeposition of porous silver onto a palladium membrane. J. Solid State Electrochem. 24, 2789-2796 (2020) 
37. D. Mislov, M. Cifrek, I. Krois, H. Dzapo, Measurement of dissolved hydrogen concentration with Clark electrode. IEEE Sens. Appl. Symp. 504-508 (2015)

38. C.P. Lu, C.T. Lin, C.M. Chang, S.H. Wu, L.C. Lo, Nitrophenylboronic acids as highly chemoselective probes to detect hydrogen peroxide in foods and agricultural products. J. Agricultural Food Chem. 59, 11403-11406 (2011)

39. J. Weber, A.J. Wain, F. Marken, Microwire chronoamperometric determination of concentration, diffusivity, and salinity for simultaneous oxygen and proton reduction. Electroanalysis 27, 1829-1835 (2015)

40. T.E. Crozier, S. Yamamoto, Solubility of hydrogen in water, sea water, and sodium chloride solutions. J. Chem. Eng. Data 19, 242-244 (1974)

41. E. Madrid, C. Harabajiu, R.S. Hill, K. Black, L. TorrenteMurciano, A.J. Dickinson, P.J. Fletcher, K.I. Ozoemena, A.K.
Ipadeola, E. Oguzie, C.O. Akalezi, F. Marken, Indirect formic acid fuel cell based on a palladium or palladium-alloy film separating the fuel reaction and electricity generation. ChemElectroChem 8, 378-385 (2021)

42. S. Das, A. Mishra, M.M. Ghangrekar, Production of hydrogen peroxide using various metal-based catalysts in electrochemical and bioelectrochemical systems: mini review. J. Hazardous Toxic Radioactive Waste 24, 06020001 (2020)

43. A. Akram, G. Shaw, R.J. Lewis, M. Piccinini, D.J. Morgan, T.E. Davies, S.J. Freakley, J.K. Edwards, J.A. Moulijn, G.J. Hutchings, The direct synthesis of hydrogen peroxide using a combination of a hydrophobic solvent and water. Catal. Sci. Technol. 10, 8203-8212 (2020)

Publisher's Note Springer Nature remains neutral with regard to jurisdictional claims in published maps and institutional affiliations. 